Wun dan Masman: Pengaruh Lingkungan Kerja, Penilaian Kinerja, Gaya Kepemimpinan...

\title{
Pengaruh Lingkungan Kerja, Penilaian Kinerja, Gaya Kepemimpinan Terhadap Kepuasan Kerja Karyawan FEB Universitas Tarumanagara Di Jakarta
}

\author{
Mariana Olivia Wun dan Ronnie Resdianto Masman \\ Program Studi Manajemen Fakultas Ekonomi Universitas Tarumanagara, Jakarta \\ e-mail : marianaolivia98@yahoo.com
}

\begin{abstract}
This study aims to analyze and test how the influence of the work environment, performance appraisal, leadership style on employee job satisfaction at the FEB Tarumanagara University in Jakarta. The data source of this study is a primary data source using the Probability Sampling data collection method. The object of this research is all permanent employees who have been chosen with a population of 40 people. Calculation of the data in this study was calculated using SmartPLS 3 analysis tools. The results of the study indicated that the work environment, performance assessment, and leadership style had a significant influence on employee satisfaction. This is evidenced from the results of hypothesis testing (t test) which shows the significance value of the independent variable.
\end{abstract}

Keywords: Work Environment, Performance Assessment, Leadership Style, Job Satisfaction

Abstrak: Penelitian ini bertujuan untuk menganalisis dan menguji bagaimana pengaruh lingkungan kerja, penilaian kinerja, gaya kepemimpinan terhadap kepuasan kerja karyawan pada FEB Universitas Tarumanagara di Jakarta. Sumber data penelitian ini merupakan sumber data Primer dengan menggunakan metode pengumpulan data Probability Sampling. Objek penelitian ini adalah seluruh karyawan tetap yang telah dipilih dengan populasi sebanyak 40 orang. Perhitungan data dalam penelitian ini dihitung menggunakan alat analisis SmartPLS 3. Hasil penelitian menujukan bahwa lingkungan kerja, penilaian kinerja, dan gaya kepemimpinan memiliki pengaruh yang signifikan terhadap kepuasan karyawan. Hal ini dibuktikan dari hasil pengujian hipotesis (uji t) yang menunjukan nilai signifikasi dari variabel bebas.

Kata Kunci: Lingkungan Kerja, Penilaian Kinerja, Gaya Kepemimpinan, Kepuasan Kerja 


\section{PENDAHULUAN}

Keberadaan karyawan yang adalah sebagai sumber daya sangat penting dalam perguruan tinggi saat ini karena sumber daya manusia dapat menunjang melalui karya, bakat, kreativitas, dorongan, dan peran nyata. Untuk mencapai tujuan perusahaan diperlukan karyawan yang sesuai dengan persyaratan dalam perusahaan, dan juga harus mampu menjalankan tugas-tugas yang telah ditentukan oleh perusahaan. Dalam melaksanakan suatu pekerjaan ada istilah kepuasan kerja dan pelaksanaan kegiatan dari pekerjaan tersebut. Kepuasan kerja adalah persoalan umum pada setiap unit kerja. Suatu pekerjaan pasti memerlukan seorang karyawan, dan karyawan tersebut haruslah memiliki pengetahuan yang luas serta berkinerja baik. Diketahui bahwa UU No. 11 tahun 1992 yang membicarakan tentang dana pensiun menyebutkan bahwa hak atas manfaat pensiun dengan catatan batas usia pensiun normal adalah 55 tahun dan batas usia pensiun wajib maksimum 60 tahun.

Anwar Prabu Mangkunegara (2009:67) menyatakan bahwa: "Faktor yang mempengaruhi pencapaian kinerja adalah faktor kemampuan (ability) dan faktor motivasi (motivation). Sedangkan menurut Keith Davis dalam Anwar prabu Mangkunegara (2009:67) dirumuskan bahwa faktor-faktor yang dapat mempengaruhi kinerja adalah : Human Performance = Ability + Motivation,

Faktor yang berpengaruh terhadap kepuasan kerja karyawan adalah faktor lingkungan kerja. Lingkungan yang dibina dalam FEB Universitas Tarumanagara diperlukan untuk mencapai tujuan perusahaan, karena dengan lingkungan kerja yang nyaman dan fasilitas karyawan yang terpenuhi akan mendorong karyawan untuk melakukan pekerjaan dengan optimal. Menurut Nitisemito (2004: 183) "lingkungan kerja adalah segala sesuatu yang berada di sekitar para pekerja dan yang dapat mempengaruhi dirinya dalam menjalankan tugas-tugas yang diembankan kepada karyawan”. Lingkungan kerja yang baik akan membuat perasaan karyawan menjadi lebih nyaman dan aman sehingga pekerjaan dapat diselesaikan tepat pada waktunya. 


\section{KAJIAN TEORI}

Lingkungan Kerja. Nitisemito dalam Nuraini (2013:97) menyatakan bahwa lingkungan kerja adalah segala sesuatu yang ada disekitar karyawan dan dapat memengaruhinya dalam menjalankan tugas yang diembankan kepadanya. Misalnya dengan adanya air conditioner (AC), penerangan yang memadai dan lain sebagainya. Isyandi (2004 : 134) menyatakan bahwa, lingkungan kerja adalah segala sesuatu yang ada di lingkungan para pekerja yang dapat memengaruhi dirinya dalam menjalankan tugas seperti temperatur, kelembapan, ventilasi, penerangan, kegaduhan, kebersihan tempat kerja dan memadai tidaknya alat-alat perlengkapan kerja. Selain ini menurut Simanjuntak (2003:39), ia menyatakan bahwa, lingkungan kerja dapat diartikan sebagai keseluruhan alat perkakas yang dihadapi, lingkungan sekitarnya dimana seorang bekerja, metode kerjanya, sebagai pengaruh kerjanya yang baik sebagai perorangan maupun sebagai kelompok.

Adapun faktor-faktor yang mempengaruhi lingkungan kerja seperti yang dikemukakan oeh Sedarmayanti (2001:21-23) meliputi (1) Penerangan/cahaya di tempat kerja, (2) Kelembapan udara di tempat kerja, (3) Sirkulasi udara di tempat kerja, (4) Dekorasi di tempat kerja, (5) Keamanan di tempat kerja.

Variabel lingkungan kerja secara operasional diukur dengan 10 faktor berikut ini menurut Sedarmayanti (2009 :26) yaitu (1) Penerangan/pencahayaan, (2) Temperatur/suhu udara, (3) Kelembapan, (4) Sirkulasi udara, (5) Kebisingan (6) Getaran mekanis, (7) Bau tidak sedap, (8) Pewarnaan, (9) Dekorasi dan music, (10) Keamanan.

Penilaian Kinerja. Menurut Snell dan Bohlander (2010: p362), "Performance appraisal can be defined as an assessment process designed to help employees understand the roles, goals, expectations, and success of the performance held regularly. 'Menurut Prof. Dr. $\mathrm{H}$. Veithzal Rivai dan Ella Jauvani Sagala, S.Psi.,M.Sc. (2009) Kinerja merupakan suatu fungsi dari motivasi dan kemampuan. Untuk menyelesaikan tugas atau pekerjaan seseorang haruslah memiliki derajat kesediaan dan tingkat kemampuan tertentu. Kesediaan dan keterampilan seseorang tidaklah cukup efektif untuk mengerjakan sesuatu tanpa pemahaman yang jelas tentang apa yang dikerjakan dan bagaimana mengerjakannya. Selain itu menurut Mathis dan Jackson (2006: p382), "Performance appraisal is a process of evaluating how well employees do their work compared to a set of standards, and then communicate that 
information to employees. Performance appraisal is also called employee ranking, employee evaluation, performance review, performance evaluation and outcome assessment."

Terdapat beberapa indikator dalam penilaian kinerja menurut Simamora (2004: 458) yaitu : (1) Loyalitas, (2) Semangat Kerja, (3) Kepemimpinan, (4) Kerja Sama, dan (5) Prakarsa.

Menurut Dessler (2008:293) ada beberapa alasan perusahaan dalam melakukan penilaian kinerja, yaitu: (1) Berdasarkan pandangan praktis, (2) Penilaian memainkan peran integral dalam performa manajemen proses perusahaan, (3) Penilaian memberikan atasan dan bawahan untuk mengembangkan sebuah rencana untuk mengoreksi berbagai kekurangan, dan untuk memperkuat hal-hal yang telah dilakukan bawahan dengan baik dan benar. (4) Penilaian akan membantu sebuah tujuan perencanaan karir yang berguna. Atau untuk memberikan kesempatan kepada para karyawan untuk mengulas perencanaan karir karyawan dalam cakupan kekuatan dan kelemahan tersebut.

Gaya Kepemimpinan. Kepemimpinan (Leadership) merupakan fungsi ketiga dari fungsi dasar manajemen. Menurut Gary Yukl (2015:9) dalam bukunya yang berjudul "Kepemimpinan dalam Organisasi" menyatakan : Kepemimpinan adalah proses untuk memengaruhi orang lain untuk memahami dan menyetujuii apa yang dibutuhkan untuk melaksanakan tugas dan bagaimana melaksanakan tugas tersebut, serta proses untuk memfasilitasi upaya individu dan kolektif guna untuk mencapai tujuan Bersama. Sedangkan Terry dalam Wahjosumidjo, (1994:25) menyatakan bahwa "Leadership is the activity of infuencing exercised to strive willingly for group objectives". Dari pendapat Terry, dapat diartikan bahwa kepemimpinan itu adalah merupakan kemampuan untuk mempengaruhi dan menggerakkan orang lain untuk mencapai tujuan.

Setelah menguraikan pengertian tentang kepemimpinan, selanjutnya menjelaskan definisi gaya kepemimpinan. Menurut Thoha (2013:49), gaya kepemimpinan merupakan norma perilaku yang digunakan oleh seseorang pada saat orang tersebut mencoba mempengaruhi perilaku orang lain seperti yang dia lihat. Sedangkan Rivai (2014:42) menyatakan gaya kepemimpinan merupakan sekumpulan ciri yang digunakan oleh pimpinan untuk memengaruhi bawahannya agar sasaran organisasi tercapai atau gaya kepemimpinan adalah pola perilaku dan strategi yang disukai dan sering diterapkan oleh seorang pemimpin. 
Dimensi gaya kepemimpinan menurut Luthans (2005 : 557) adalah gaya kepemimpinan teori Path-Goal (Jalan Tujuan), yaitu : (1) Kepemimpinan Direktif, (2) Kepemimpinan Suportif Menurut Robert Tannenbaum dan Warren H. Schmidt (1958) yang dikutip dari buku Wirawan (2013) dalam mengungkapkan terdapat indikator gaya kepemimpinan, yaitu : (1) Perilaku Berorientasi Tugas (Task Oriented), (2) Perilaku Berorientasi Hubungan (Relationship Oriented)

Kepuasan Kerja. Menurut Malayu (2011 : 202 ), ia menyatakan bahwa kepuasan kerja adalah sikap emosional yang menyenangkan dan mencintai pekerjaannya. Sikap inilah yang akan dicerminkan oleh karyawan melalui moral kerja, kedisiplinan dan prestasi kerja karyawan. Menurut Kreitner dan Kinicki (2008), "Job satisfaction is an effective emotional response or for various aspects of work."

Stephen P. Robbins (2007:73) dalam bukunya berjudul "Organizational Behavior" menyatakan bahwa "Job Satisfaction can be defined as a positive feeling about one's job resulting an evaluation of its characteristic". Pendapat lain Luthans (2011 : 141 ) mengatakan bahwa kepuasan kerja adalah "states that job satisfaction is a set of rules concerning fun and unpleasant feelings related to their work."

Untuk mengetahui indikator apa saja yang mempengaruhi kepuasan keja, menurut Nasution dan Saydam (2011:5), terdiri dari : (1) Pekerjaan, (2) Gaji, (3) Promosi, (4) Supervisi.

Dimensi kepuasan kerja menurut Smith, Kendall \& Hulin (dalam Luthans 2006 : 243 ), yaitu : (1) Pekerjaan itu sendiri (Work it self), (2) Atas (Supervisor), (3) Teman sekerja (Workers), (4) Promosi (Promotion), dan (5) Gaji/Upah (Pay).

\section{Hipotesis}

Berdasarkan kajian - kajian diatas dapat disusun hipotesis sebagai berikut :

$\mathrm{H}_{1:}$ Lingkungan kerja mempunyai pengaruh positif yang signifikan terhadap kepuasan kerja karyawan di FEB Universitas Tarumanagara.

$\mathrm{H}_{2}$ : Penilaian kinerja mempunyai pengaruh positif yang signifikan terhadap kepuasan kerja karyawan di FEB Universitas Tarumanagara. 
$\mathrm{H}_{3}$ : Gaya kepemimpinan mempunyai pengaruh positif yang signifikan terhadap kepuasan kerja karyawan di FEB Universitas Tarumanagara.

$\mathrm{H}_{4}$ : Lingkungan kerja, penilaian kinerja, dan kepuasan kerja secara Bersama - sama mempunyai pengaruh positif yang signifikan terhadap kepuasan kerja karyawan di FEB Universitas Tarumanagara.

Dengan model kerangka pemikiran dari penelitian ini seperti dalam gambar 1 berikut ini :

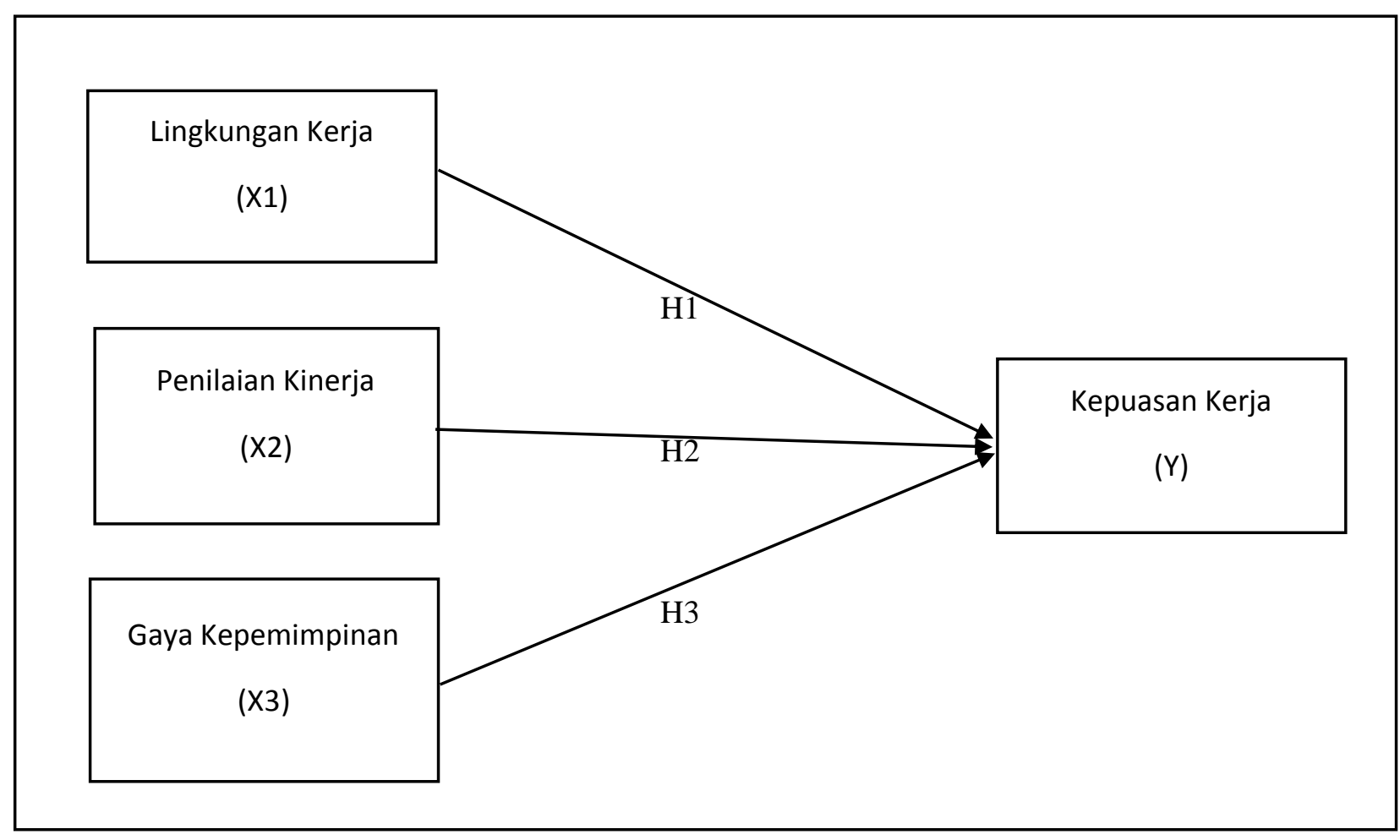

Gambar 1 . Kerangka Pemikiran

\section{METODE}

Waktu dan Tempat Peneltian. Penelitian ini dilakukan selama 4 bulan sejak Februari 2019 hingga Juni 2019 pada FEB Universitas Tarumanagara di Jakarta dengan populasi sebanyak 40 orang karyawan tetap.

Desain Penelitian. Desain penelitian yang digunakan dalam penelitian ini menggunakan penelitian kausal. Penelitian Kausal adalah penelitian yang terdapat hubungan sebab dan 
akibat dimana variable independent mempengaruhi variable dependen (Sekaran dan Bogie, 2013) dan (Ghazali, 2011). Penelitian ini merupakan penelitian untuk mengetahui variable independen yaitu lingkungan kerja, penilaian kinerja, gaya kepemimpinan terhadap variabel dependen yaitu kepuasan kerja.

Skala Pengukuran Variabel. Pengukuran variabel dalam penelitian ini menggunakan skala interval. Pengumpulan data dilakukan dengan wawancara melalui kuesioner dengan menjawab pertanyaan - pertanyaan dengan menggunakan skala interval sebagai berikut : Skor 5 untuk jawaban sangat setuju, Skor 4 untuk jawaban setuju, Skor 3 untuk jawaban cukup setuju, Skor 2 untuk jawaban tidak setuju, Skor 1 untuk jawaban sangat tidak setuju.

Populasi dan Sampel Penelitian. Populasi dari penelitian ini adalah karyawan tetap FEB Universitas Tarumanagara. Teknik pengambilan sampel adalah dengan mengunakan probability sampling. Menurut Sugiyono (2012:92), Probability Sampling merupakan suatu teknik pengambilan sampel yang memberikan kesempatan atau peluang yang sama untuk setiap anggota dan unsur populasi untuk dipilih menjadi anggota sampel. Atau dengan kata lain teknik ini akan memberikan peluang yang sama terhadap semua populasi untuk menjadi sampel.

Metode Pengumpulan Data. Dalam penelitian ini teknik pengumpulan data yang digunakan yaitu dengan penelitian lapangan (Field Research) dengan melakukan penyebaran kuesioner. Jenis data yang digunakan adalah data primer dari pengisian kuesioner. Teknik analisis data dalam penelitian ini adalah analisis regresi linier berganda dengan menggunakan program SmartPLS ver 3 for Windows.

\section{HASIL DAN PEMBAHASAN}

Hasil Uji Kualitas Instrumen. Dalam pengujian validitas dengan menggunakan software SmartPLS ver 3 for Windows. Syarat minimum untuk dianggap dapat memenuhi syarat adalah jika faktor loading yang berada pada setiap indikator, yang kemudian dianggap valid apabila memilki nilai $>0.7$, tetapi minimalnya 0.5 - 0.6 masih dianggap cukup dan masih dapat diperbolehkan untuk digunakan (Malhotra, 2010). Agar analisis dari faktor dapat digunakan, maka nilai dari communality dan Average Variance Extracted (AVE) harus > 0.5 . 
Hasil Uji Hipotesis dan Analisis Data. Analisis yang digunakan untuk pengujian hipotesis dalam penelitian ini terbagi menjadi uji validitas, uji reliabilitas, koefisien determinasi, dan Uji Goodness of Fit (GOF).

Hasil Uji Validitas Konvergen (Outer Loading). Hasil uji validitas konvergen dalam penelitian ini dapat diketahui bahwa nilai outer loading yang diolah dengan menggunakan perangkat lunak SoftwareSmartPLS ver 3 for windows ini menunjukkan berada pada tingkat nilai yang cukup atau berada pada nilai yang diperbolehkan, yaitu >0.5. Nilai outer loading yang dimiliki paling kecil adalah 0.710 yang berada pada indikator penilaian kinerja (X23). Dengan demikian indikator yang digunakan pada penelitian ini adalah valid dan telah memenuhi uji validitas konvergen outer loading.

Hasil uji Validitas Konvergen (Average Variance Extracted dan communality). Pada penelitian ini diketahui bahwa nilai AVE dari setiap variabel adalah lebih besar dari 0.5 sehingga dapat ditarik kesimpulan bahwa semua variabel telah memenuhi persyaratan.

Hasil Uji Reliabilitas (Cronbarch's Alpha). Hasil uji reliabilitas dalam penelitian ini diketahui bahwa, seluruh hasil Cronbach's Alpha dari setiap pernyataan untuk variabel lingkungan kerja, penilaian kinerja, gaya kepemimpinan dan kepuasan kerja memilki hasil $>$ 0,6. Maka, dapat disimpulkan bahwa seluruh variabel yang digunakan dalam penelitian ini telah reliabel.

Hasil Pengujian Signifikansi Dengan Metode Bootstrap (uji t). Hasil pengujian uji t adalah :

1. Dari hasil pengujian variabel X1 (Lingkungan Kerja) terhadap variable Y (Kepuasan Kerja) memiliki nilai $\mathrm{T}$-Statistics sebesar 2.129, maka $\mathrm{H}_{1}$ di terima karena $\mathrm{T}$-Statistics lebih besar dari T-value 1,96. Maka dapat disimpulkan Lingkungan Kerja memiliki pengaruh yang signifikan terhadap Kepuasan kerja karyawan FEB Universitas Tarumanagara di Jakarta.

2. Dari hasil pengujian variabel X2 (Penilaian Kinerja) terhadap variable Y (Kepuasan Kerja) memiliki nilai T-Statistics sebesar 2.125 maka $\mathrm{H}_{2}$ diterima karena T-Statistics lebih besar dari T-Value 1,96. Maka dapat disimpulkan Penilaian Kinerja memiliki pengaruh yang signifikan terhadap Kepuasan kerja karyawan FEB Universitas Tarumanagara di Jakarta 
3. Dari hasil pengujian variabel (Gaya Kepemimpinan) terhadap variable Y (Kepuasan Kerja) memiliki nilai T-Statistics sebesar 3.203, maka $\mathrm{H}_{3}$ diterima karena T-Statistics lebih besar dari T-value 1,96. Maka dapat disimpulkan Gaya Kepemimpinan memiliki pengaruh yang signifikan terhadap Kepuasan kerja karyawan FEB Universitas Tarumanagara di Jakarta.

Hasil Uji Koefisien Determinasi $\left(\mathbf{R}^{2}\right)$. Dari hasil uji koefisien determinasi $\mathbf{R}^{2}$ dari penelitian ini dapat diketahui besarnya koefisien determinasi $\left(\mathrm{R}^{2}\right)$ adalah sebesar 0,866 yang memiliki arti bahwa sebesar 86.6\% variabel dependen Kepuasan Kerja dapat dijelaskan oleh variabel independen Lingkungan Kerja, Penilaian Kinerja, dan Gaya Kepemimpinan Sisanya sebesar $13.4 \%$ dapat dijelaskan oleh variabel lain.

Hasil Uji Goodness of Fit (GOF). Uji Goodness of Fit (GOF) bertujuan untuk menilai ketepatan model baik atau tidak nya model tersebut. Kriteria Goodness of Fit dalam SmartPLS 3 dapat dinilai berdasarkan Normed Fix Index (NFI). NFI merupakan salah satu pengukuran dalam mengukur fit atau tidaknya suatu model penelitian. Nilai NFI bertujuan untuk melihat apakah ketepatan model baik atau tidak. Dalam penelitian ini diketahui nilai GOF adalah 0.393 .

Pengaruh Lingkungan Kerja terhadap Kepuasan Kerja Kayawan. Dalam penelitian ini diketahui bahwa lingkungan kerja berpengaruh positif terhadap kepuasan kerja pada karyawan FEB Universitas Tarumanagara. Dilihat dari hasil Output Bootstrapping pengaruh langsung, menunjukkan hasil pengujian variabel X1 (Lingkungan) terhadap variable Y (Kepuasan Kerja) memiliki nilai T-Statistics sebesar 2.129, dengan nilai tersebut maka $\mathrm{H}_{1}$ di terima atau karena T-Statistics lebih besar dari T-value 1,96. Hasil ini didukung oleh penelitian Quinerita Stevani Aruan dan Mahendra Fakhri (2015) bahwa lingkungan kerja memiliki pengaruh yang signifikan terhadap kepuasan kerja pada karyawan FEB Universitas Tarumanagara.

Pengaruh Penilaian Kinerja terhadap Kepuasan Kerja Karyawan. Dalam penelitian ini diketahui bahwa penilaian kinerja berpengaruh positif terhadap kepuasan kerja pada Karyawan FEB Universitas Tarumanagara. Dilihat dari hasil Output Bootstrapping pengaruh langsung, menunjukkan hasil pengujian variabel X2 (Penilaian Kinerja) terhadap variable Y (Kepuasan Kerja) memiliki nilai T-Statistics sebesar 2.125 maka $\mathrm{H}_{2}$ diterima 
karena TStatistics lebih besar dari T-Value 1,96. Hasil penelitian ini juga sama dengan penelitian terdahulu yang dilakukan oleh Cindi Ismi Januar, dkk (2015) bahwa penilaian kinerja memiliki pengaruh yang signifikan terhadap kepuasan kerja pada karyawan FEB Universitas Tarumanagara.

Pengaruh Gaya Kepemimpinan terhadap Kepuasan Kerja Karyawan. Gaya Kepemimpinan berpengaruh positif terhadap Kepuasan Kerja karyawan FEB Universitas Tarumanagara. Dilihat dari hasil Output Bootstrapping pengaruh langsung, menunjukkan hasil pengujian variable M (Kinerja) terhadap variable Y (Kepuasan Kerja) memiliki nilai T-Statistics sebesar 3.203, maka $\mathrm{H}_{2}$ tidak di terima karena T-Statistics lebih besar dari Tvalue 1,96. Hasil ini didukung oleh penelitian dari Elsa Eria bahwa gaya kepemimpinan memiliki pengaruh yang signifikan terhadap kepuasan kerja pada karyawan FEB Universitas Tarumanagara.

Dari hasil evaluasi inner model, besarnya koefisien determinasi $\left(\mathrm{R}^{2}\right)$ adalah sebesar 0.866 yang memiliki arti bahwa sebesar 86.6\% variabel dependen Kepuasan Kerja dapat dijelaskan oleh variabel independen Lingkungan Kerja, Penilaian Kinerja dan Gaya Kepemimpinan. Sisanya sebesar $13.4 \%$ dapat dijelaskan oleh variabel lain.

\section{PENUTUP}

Kesimpulan. Berdasarkan hasil analisis yang telah diuraikan, maka dapat disimpulkan sebagai berikut:

1. Lingkungan Kerja berpengaruh positif dan signifikan terhadap Kepuasan Kerja karyawan di FEB Universitas Tarumanagara

2. Penilaian Kinerja berpengaruh positif dan signifikan terhadap Kepuasan Kerja karyawan di FEB Universitas Tarumanagara

3. Gaya Kepemimpinan berpengaruh positif dan signifikan terhadap Kepuasan Kerja karyawan di FEB Universitas Tarumanagara

Implikasi. Sebagai implikasi dari penelitian ini disarankan perlu dilakukan penelitian lebih lanjut terhadap variabel - variabel tersebut dan variabel - variabel lainnya yang belum diamati dalam penelitian ini secara kontinyu agar bisa dimanfaatkan oleh kebijakan di Universitas Tarumanagara. 


\section{DAFTAR PUSTAKA}

A.A. Anwar Prabu Mangkunegara. 2009. Manajemen Sumber Daya Manusia. Bandung: PT. Remaja Rosdakarya.

Alex S. Nitisemito, 2004, Manajemen Personalia, Ghalia Indonesia, Jakarta.

Aruan, Quinerita Stevani, Mahendra Fakhri, 2015, "Pengaruh Lingkungan Kerja terhadap kepuasan kerja karyawan Lapangan Departemen Grasberg Power Distribution PT. FREEPORT INDONESIA", Jurnal Modus , Vol.27, No.2.

Aria, Elsa. 2015. "Pengaruh Gaya Kepemimpinan Terhadap Kepuasan Kerja Karyawan pada PT. SBS (Sari Buah Rawit) Kecamatan KInali Kabupaten Pasaman Barat"

Bohlander, George., and Snell, Scott. (2010). Principles of Human Resource. Management, 15th ed. Mason, OH: South Western - Cengage Learning.

Davis, Keith dan Newstrom, 2014, Perilaku Dalam Organisasi, Edisi ketujuh, Penerbit. Erlangga, Jakarta.

Dessler, Garry. 2008. Human Resources Management. 11th Edition. New Jersey : Pearson Education, Inc.

Fred Luthans, (2006), Perilaku Organisasi. Edisi Sepuluh, PT. Andi: Yogyakarta.

Ghozali, Imam. (2011). Aplikasi Analisis Multiariate dengan Porogram IBM SPSS 20. Semarang. Badan Penerbit Universitas Diponegoro.

Henry, Simamora, 2004, Manajemen Sumber Daya Manusia, Edisi Ketiga, Yogyakarta, STIE YPKN.

Hasibuan, Malayu S.P., 2011. Manajemen Sumber Daya Manusia. Bumi Aksara, Jakarta.

Isyandi, B, 2004. Manajemen Sumber Daya Manusia Dalam Perspektif Global. Pekanbaru, Unri Press.

Januari, Cindy Ismi, Hamidah Nayati Utami Ika Ruhana, 2015. "Pengaruh Penilaian Kinerja Terhadap Kepuasan Kerja dan Prestasi Kerja”, Jurnal Administrasi Bisnis (JAB)|Vol. 24 No. 2 Juli 2015.

Kreitner, Robert dan Kinicki. 2008. Organizational Behavior. 8th Edition. Boston: McGraw-Hill.

Luthans, Fred. 2005. Organizational Behavior. 10th Edition. Alih Bahasa: Vivin Andhika, dkk. Yogyakarta: ANDI

Miftah, Thoha. (2013). Prilaku Organisasi Konsep Dasar Dan Implikasinya.

Jakarta : PT. Raja Grafindo Persada

Malhotra, Naresh K.(2010). Riset Pemasaran (Marketing Research) (Edisi 4 Jilid 1) New Jersey, Indonesia: PT. Indeks

Mathis, R.L. \& J.H. Jackson. 2006. Human Resource Management: Manajemen Sumber Daya Manusia. Terjemahan Dian Angelia. Jakarta: Salemba Empat.

Nuraini, T. 2013. Manajemen Sumber Daya Manusia, Yayasan Aini Syam: Pekanbaru.

Prof. Dr. H. Veithzal Rivai, M.B.A \& Ella Jauvani Sagala, S.Psi.,M.Sc., 2009. Manajemen Sumber Daya Manusia untuk Perusahaan. Edisi Kedua. Jakarta : Penerbit PT. Raja Grafindo Persada.

Robbins, Stephen P. dan Judge. 2007. Perilaku Organisasi, Jakarta : Salemba Empat. Hal 22.

Rivai, Veithzal. 2014. Manajemen Sumber Daya Manusia untuk Perusahaan, Edisi ke 6, PT. Raja Grafindo Persada, Depok, 16956

Simanjuntak, Payaman J, 2003, Produktivitas Kerja Pengertian dan Ruang Lingkupnya, Prisma, Jakarta. 
Sedarmayanti. 2001. Sumber Daya Manusia dan Produktivitas Kerja. Bandung : Mandar Maju

Sedarmayanti. 2009. Sumber Daya Manusia dan Produktivitas Kerja. Bandung: CV Mandar Maju.

Sekaran, U. Dan Bougie, R (2013). Research Methods For Bussiness : A Skill Building Approach. New York: JohnWilkey \& Sons. Inc.

Sugiyono. 2012. Metode Penelitian Kuantitatif Kualitatif dan R\&D. Bandung: Alfabeta.

Tannenbaum, R. Weschler, I. dan Massarik, F. 2013. Leadership and Organization. Los Angeles, Routledge

Wahjosumidjo. 1994. Kepemimpinan dan Motivasi. Ghalia Grafindo. Jakarta

Yukl, Gary. 2015. Kepemimpinan Dalam Organisasi. Edisi Ketujuh. (Ati Cahayani, Trans). Jakarta: PT. Indeks. 